\title{
The skillful grasp of rhythm in stage performance
}

\author{
Ning Lei $i^{1, a}$ \\ ${ }^{1}$ School of music and dance, Qujing Nornal University, Yunnan, China, 655011 \\ acomsasla@163.com
}

Keywords: Stage performance; rhythm; grasp

\begin{abstract}
In real life, we all have their own rhythm, embodied in our way of life, way of working, thinking on the action, these acts affect the pace of our lives. The creation of stage performance is taken from the details of life, which is different from life. The influence of rhythm on the stage performance will affect the performance of the whole stage, and the key to the success of the drama is to grasp the rhythm of the performance. The rhythm of the actors in the stage drama performance is the grasp of the theme of the work. The actor's grasp of the inner emotion, and the actor's grasp of the action. Therefore, the grasp of rhythm plays an important role in the healed stage performance. This paper discusses ways to grasp the rhythm in the stage performance.
\end{abstract}

\section{Introduction}

Rhythm is reflected in all aspects of life. It is everywhere, affecting people's way of life and work [1]. And the rhythm of the stage plays a direct impact on the performance of the stage, the influence of the main theme of the works. Is the importance of the stage drama in rhythm, a rhythm is pushing the performances of the plot, the whole drama to be reasonable in all aspects are closely linked, and unobtrusive, to create a comfortable and harmonious stage environment. But simply rely on the way to the soliloquy story at forward, but also with the rhythm, such as drama story begins, soothing rhythm can be introduced to the audience in a theatrical performance, to the development of the story, suddenly tight suddenly slow pace, can drive the emotions of the audience, the story the climax is the most prominent rhythm, it can grasp the psychology of the audience, the audience's thoughts into work, make the audience a feeling personally on the scene. Two are the rhythm should be combined with the actor drama performances in the form of body movement and language expression, only perfect rhythm together to make the actors more attractive, the stage drama more infectious. To match the rhythm of different actors in the stage drama, and his emotions, such as sadness when the cry, happy when the form such as cheerful as a lark and so on, can increase the charm of drama. Three is to express the drama of the characters in the works of thoughts and feelings, it shall cooperate with the rhythm, so it plays an important role for the character, show the character's behavior characteristics, it will feature the character image convey to the audience, let the audience have a more specific understanding of the characters in the works, it's easier to understand the works of prominent theme.

\section{The concrete manifestation of rhythm in stage performance}

Theatrical performances in the process, with the change of stage lighting, sound, background and singing, the actors on the stage dance, action characters need to grasp the rhythm of the rhythm, good or bad will directly affect the drama stage, its specific manifestations are as follows:

A. Combinations of internal and external rhythm

Internal rhythm is often referred to as the psychological rhythm of the characters, refers to the dramatic works of the characters in the hearts of emotional changes, including emotions, responsive changes in the speed, etc.. The external rhythm refers to the dramatic changes in the Chinese and foreign drama, which can be manifestly perceived. During a theatrical performance, internal rhythm and external rhythm is the combination of the speed change speed change will affect the internal rhythm and external rhythm, including body movement, language use, and the change of external rhythm can affect internal rhythm through body movements and dialogue. The internal rhythm is 
invisible to the performers have a unique insight and understanding of the works, so as to the characters in the novel interpretation of the most incisive, and changes in the external rhythm is external, obviously, it will change with the internal rhythm. In general, relative to the internal rhythm and external rhythm, the change is more complicated, because the external rhythm to timely change according to the interactive atmosphere and the audience, because of many external factors on the change, it will affect the change of the internal rhythm. Therefore, the relationship between the two subtle, indispensable [2].

B. Body rhythms

The role of body rhythm is very important in the performance of a stage play, the body movement is the stage drama performance in order to achieve the role of the grasp and control. The grasp of the rhythm of the body can make drama performance more specific and vivid image. The deduction of all body movements is the grasp of the content and the theme of the work, from the inside out to show the charm of the work. Drama actor on the stage of every move, a look up, a foot all belong to body movements. For most people, the rhythm with integrity, the integrity is the theatrical performances in the process not only focus on a movement of the body is perfect or not, but during the performance for the body has a good grasp of rhythm, make every body movements and changes of complete and coherent throughout the show in [2]. That just says, the cohesion of each action should be coherent, the end of a body action, the next body movement began, there is no pause in the middle. A rhythm rhythm and form a rhythm must be closely connected, so as to achieve the role of connecting a body rhythm do foreshadowing and accumulation of power in order to complete a form of rhythm better, thus the whole drama performances has better appreciate the value and appeal to to attract the audience and the viewers. Susan Lange once said: "the essence of rhythm is to prepare for a new thing by the end of a previous event" [3]. Therefore, the coherence of the body movements in the theatrical performance must be complete. For example, actors perform in singing and dancing with dance and Drama Singing requirements, dance movement must start, not simply repeat an action, nor a variety of actions without order together, there is no connection. But it should be done before the end of the action is the next generation in the formation of the precise conditions. The rhythm of the body is such a law, up and down echoes, the end of the phase, in line with the performance of the dramatic scene.

C. Language rhythms

The rhythm of language reflects the changes of the characters in the dramatic works. The rhythm of the language and the characteristics of the rhythm of the body similar to some of the stresses in the works of the language of the convergence. End of a language rhythm means that the next language is about to begin. Of course, the grasp of the rhythm of language must be a profound understanding and grasp of the content of the work, the central idea, emotional expression, the only way to achieve the rhythm of language in the performance of the drama [4]. While the rhythm of language rules mainly through two aspects, one is the stage art of dramatic creation from literary works, so the rhythm of language in literary works with a modified processed flavor, a kind of language rhythm is literature itself has. On the other hand, is through the late human processing and modification, after repeated formulation script language rhythm, this script in the rhythm of language has more stage effect, can more clearly show the characters and themes. Therefore, the stage in the drama script language rhythm according to the script of the language rhythm, reasonable grasp the inner emotional changes in the works and works of people play the theme, the only way to work the rhythm of language expression in place, can make the person character alive on the stage. The rhythm of language in the works of literature and the rhythm of the script and the lines of the language influence each other. Between the two is the rhythm of the language be made one, although different, but the meaning of the expression and the central idea is the same, which are common to the stage drama, the stage drama to show greater charm and appeal, make the audience pay more attention to the art of drama.

D. Overall rhythms

In addition to the combination of internal and external rhythm, the rhythm and the rhythm of language, it is very important to grasp the whole rhythm of the dramatic performance in the [5]. The creation of the characters in the drama requires that the actor must understand the content of the work, realize the author's conception, grasp the whole rhythm according to his understanding of the work 
and the character and personality of the characters. Only by grasping the entire rhythm of the drama can we show the charm and attraction of the drama. The entire rhythm of the play determines the final result of the play. If the unbroken rhythm of a play is not well grasped, it will directly affect the result of the whole drama. Especially in the role of conflicts and contradictions, some of the main supporting role, which requires performers from the point of view of the whole drama, the overall rhythm, for the character of the highlights, emotional expression, plot the ups and downs to grasp and control. If we ignore the grasp of the overall rhythm in the performance of the drama, but only limited to the control of the general rhythm, it will bring bad results to the dramatic performance, which will seriously affect the charm of dramatic art. Therefore, the dramatic changes in the overall performance of the theatrical performance of the theater, so pay attention to grasp the overall situation, in order to better show the appeal of drama.

\section{Factors affecting the rhythm of dramatic performance}

In the stage performance, the influence of the rhythm of the various factors, there are major, there are secondary, there are subjective factors, there are objective factors. The drama is a complex process, it requires the performer to dramatic works content, character, the central idea of the overall grasp of the rhythm, integrating these into play, the subsequent analysis of the influencing factors of dramatic rhythm.

\section{A. Characters}

There are no two identical leaves in the world, and there is not really the same as the two characters. Everyone is the only song of the individual, the personality is different, some people optimistic, there are people pessimistic, some people lively and cheerful, but also some implicit [6]. Personality determines the role of the character in the drama, and then affects the rhythm of the dramatic performance. For example: on behalf of Peking Opera in the works as the "tiger", the protagonist Yang Zirong's witty and courageous performer to seize Yang Zirong's character, with the stage props and stage lighting, the performers will figure the interpretation of the most incisive, the characters also highlighted in front of the audience. Another example of Sichuan Opera artistes, individuality forceful personality, very outgoing and frivolous, in the role played to seize these traits. Therefore, only by grasping the individuality of the characters, can we better grasp the rhythm of the change of the drama.

B. Set the situation

Context plays a key role in stage performance. According to the content and theme of the script to suit different situations. The situation is set to the existing, fixed environment, the time, place, characters, events of the organic combination of [7]. The situation is the prerequisite for the development of the performance of the drama, the form of the performance of the characters must be performed in the context of the situation, and it will also limit the character's psychology, behavior, etc.. Effect of rhythm on the stage drama is huge, only a deep understanding and Analysis on the performance situation and characters, in order to grasp the character, find the rhythm, the infinite charm of a better interpretation of drama. The irrationality of the situation design or not, will greatly reduce the effect of the histrionic performance, reduce the quality of excellent works, which are not responsible for the performance of the drama, but also the desecration of the arts. Therefore, in the setting of the situation, we should actively respond to the theme of the work, to grasp the character, to control the rhythm of the drama, this is the love of drama and respect for the theatrical performances [8].

\section{Rhythm - the law of action in dramatic performance}

Art comes from life. Rhythm is the soul of art [9]. If regards art as a living person, so this is one of the central nervous rhythm, dominate the entire human action and language, action is the man's hands and feet, to grasp the rhythm of drama. While the action is one of the important factors of drama, the 
action law of drama is embodied in the rhythm, the stage of body movement, in the drama through the language movement and the internal and external factors combined to achieve the grasp of rhythm.

In a word, the drama as an art, drama to grasp the rhythm directly affect the dramatic artistic charm, the key is to learn so theatrical performances and rhythm, which are the comedian's basic literacy [10]. Drama actor must fully grasp the rhythm of drama, seize the personality characteristics and psychological characteristics, the drama the most incisive, will be presented to the audience vivid characters, to the audience to impress the audience, the audience can really into drama, drama interpretation of the theme. And emotion, let more and more audience attention and loves drama.

\section{References}

[1]Dressen-Hammouda D. From novice to disciplinary expert: Disciplinary identity and genre mastery[J]. English for Specific Purposes, 2008, 27(2):233-252.

[2]Mahowald M. The ethics of care: Personal, political, and global (review)[J]. International Journal of Feminist Approaches to Bioethics, 2009, 2(1):177-181.

[3]Amade-Escot C. Using the Critical Didactic Incidents Method to Analyze the Content Taught.[J]. Journal of Teaching in Physical Education, 2005, 24(2):127-148.

[4]Schelkle W. In the Spotlight of Crisis How Social Policies Create, Correct, and Compensate Financial Markets[J]. Politics \& Society, 2012, 40(1):3-8.

[5]Gharbawie O A, Auer R N, Whishaw I Q. Subcortical middle cerebral artery ischemia abolishes the digit flexion and closing used for grasping in rat skilled reaching.[J]. Neuroscience, 2006, 137(4):1107-18.

[6]Sacrey L A R, Whishaw I Q. Subsystems of sensory attention for skilled reaching: Vision for transport and pre-shaping and somatosensation for grasping, withdrawal and release[J]. Behavioural Brain Research, 2011, 231(2):356-365.

[7]Buxbaum L J, Kyle K, Grossman M, et al. Left Inferior Parietal Representations for Skilled Hand-Object Interactions: Evidence from Stroke and Corticobasal Degeneration[J]. Cortex, 2007, 43(3):411-23.

[8]Bakola S, Gamberini M, Passarelli L, et al. Cortical connections of parietal field PEc in the macaque: linking vision and somatic sensation for the control of limb action[J]. Cerebral Cortex, 2010, 20(11):2592.

[9]Deng X, Dzamko N, Prescott A, et al. Characterization of a selective inhibitor of the Parkinson's disease kinase LRRK2[J]. Nature Chemical Biology, 2011, 7(4):203-5.

[10]Davis R L, Yao J. Prediction of Compressor Stage Performance From Choke Through Stall[J]. Journal of Propulsion \& Power, 2015, 22(3):550-557. 